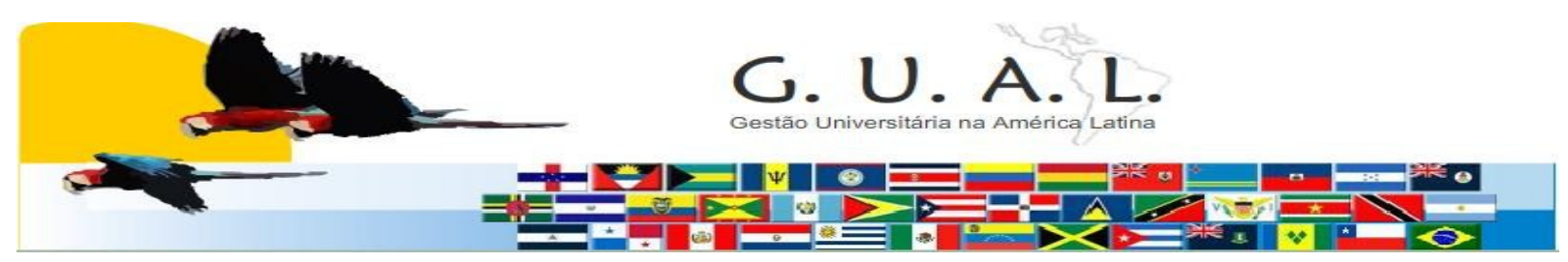

ISSN 1983-4535

\title{
FORMAÇÃO PEDAGÓGICA DE DOCENTES COMO FERRAMENTA DE GESTÃO UNIVERSITÁRIA: O CASO DA UNIVERSIDADE DE CAXIAS DO SUL
}

\author{
EDUCATIONAL TRAINING OF TEACHERS AS A TOOL OF UNIVERSITY \\ MANAGEMENT: THE CASE OF THE CAXIAS DO SUL UNIVERSITY
}

Nilva Lúcia Rech Stedile, Doutora

Universidade de Caxias do Sul nlrstedi@ucs.br

Recebido em 27/outubro/2011

Aprovado em 22/fevereiro/2012

Sistema de Avaliação: Double Blind Review

Esta obra está sob uma Licença Creative Commons Atribuição-Uso. 


\title{
RESUMO
}

Os constantes e dinâmicos desafios que emergem no contexto do mundo globalizado impõem às universidades a necessidade de aprimoramento e qualificação permanente. Para a qualificação do ensino é indispensável uma política curricular clara e flexível e a capacitação pedagógica do professor. Este estudo objetivou desenvolver e avaliar um processo de capacitação de professores para o trabalho com unidades de aprendizagem comuns aos cursos de graduação e identificar a relação existente entre a implantação curricular e as competências docentes necessárias para isso. O método de trabalho foi a elaboração coletiva de Unidades de Aprendizagem (disciplinas) comuns aos diferentes cursos de graduação e o acompanhamento do processo de operacionalização das mesmas. O modelo pedagógico da capacitação baseouse na interação (interacionista), segundo o qual cada sujeito é responsável pela (re)significação de conceitos, socialização e problematização dos mesmos. Este modelo mostrou-se produtivo, permitiu a construção de projetos consistentes com a função de cada disciplina e constituiu-se em uma oportunidade de desenvolvimento da profissionalidade docente. $\mathrm{O}$ processo permitiu reforçar o pressuposto de que o êxito da implantação de uma política curricular e de um projeto de curso depende diretamente (entre outros fatores) da capacitação técnica, científica e pedagógica dos professores.

Palavras-chave: Capacitação. Pedagógica. Formação de professores. Política curricular.

\begin{abstract}
The constant and dynamic challenges that emerge in the context of a globalized world impose on the university the need for permanent improvement and qualification. In the teaching qualification is essential a clear and flexible curriculum policy and teachers pedagogical training. This study aimed to develop and evaluate teachers training process of to work with common learning units in college courses and to identify the relationship between the implementation of curricula and teaching skills necessary to do so. The method of work was the collective development of learning units (subjects) common to the various college courses and monitoring the operational process of the same. The pedagogical model of training was based on the interaction (interactional), whereby each individual is responsible for (re) signification of concepts, socialization and questioning them. This model proved to be productive, allowed the construction of consistent projects with each subject function and consisted of an opportunity to develop the teaching profession. The process has reinforced the assumption that the successful deployment of a common curriculum and a course project directly depends on (among others) of technical, scientific and pedagogical training of teachers.
\end{abstract}

Keywords: Pedagogical training. Teacher training. Curriculum policy. 


\section{INTRODUÇÃO}

As instituições educacionais têm assumido uma posição cada vez mais essencial para o contexto em que se inserem e, com isso, a necessidade de enfrentar constantemente novos e muitos desafios. Contexto este que exige contínuo aprimoramento e renovação institucional (tanto em sua forma de organização quanto em seu modo de operar), atenção e sincronia permanentes com as necessidades sociais, produção de conhecimentos que possam contribuir tanto para o desenvolvimento da sociedade quanto para a formação de profissionais que atendam às demandas de um mundo globalizado.

Além desses aspectos, tais desafios trazem para as universidades também a exigência de promover mudanças curriculares (projetos inovadores) e uma correspondente capacitação docente, de modo que se possa redefinir os papéis de cada ator (professor, aluno e gestor acadêmico) frente à nova situação e produzir um ambiente de sala de aula que potencialize ao máximo a aprendizagem, considerando que o papel da educação superior é facilitar que cada indivíduo alcance seu máximo potencial humano e profissional. Tendo presente esses desafios, este estudo tem por objetivo propor, desenvolver e avaliar um processo de capacitação de professores para o trabalho com unidades de aprendizagem comuns a diferentes cursos de graduação e identificar a relação que existe entre o êxito na implantação de uma nova lógica curricular e as habilidades e competências docentes necessárias para isso.

Atingir esses objetivos não é tarefa fácil, quando o fim último é profissionalizar a ação docente como forma de auxiliar na consolidação de um perfil profissional de egresso e contribuir na formação profissional em qualquer área em aspectos como: (a) reflexão sobre as diferentes formas de conhecer e o papel do conhecimento; ( b) inserção ética do fazer profissional na sociedade; (c) relações entre a formação universitária e a qualidade de vida das pessoas e do planeta; (d) utilização da leitura e escrita como instrumentos a serviço da aprendizagem autônoma; (e) implicações do fazer profissional sobre a sociedade; (f) possibilidades de atuação profissional; e (g), finalmente, formas de construção do conhecimento.

Após amplas discussões e análises e considerando o perfil de aluno pretendido, foram definidas cinco unidades de aprendizagem potencialmente capazes de conduzir uma reflexão sistemática sobre aspectos considerados fundamentais na atuação de profissionais egressos do ensino superior. São as seguintes: 1) Leitura e Escrita na Formação Universitária; 2) Epistemologia; 3) Ética; 4) Seminários de Pesquisa; 5) Universidade e Sociedade. 
Definir unidades de aprendizagens (disciplinas) dentre um número ilimitado de possibilidades é uma tarefa bastante difícil uma vez que implica decidir por aquelas experiências de aprendizagem que têm maior probabilidade de compor o perfil institucional de egresso requerido. Não menos complexa, no entanto, é a tarefa de construir a proposta de trabalho para cada uma e capacitar os professores para uma atuação profissional que possibilite o cumprimento da função da disciplina no contexto da formação.

Diante do exposto, as seguintes perguntas nortearam o estudo: Que modelo de capacitação pedagógica pode ser utilizado para garantir o desenvolvimento de aprendizagens relacionadas às disciplinas comuns aos cursos de graduação da UCS? Como desenvolver essa capacitação? Que resultados podem ser observados (em relação às competências profissionais de professores) ao término do processo desenvolvido? Responder a essas questões parece contribuiu para a (re)definiçãa do papel do professor em nível superior de ensino como agente mediador da aprendizagem e elemento fundamental nos processos de construção da competência humana e profissional.

\section{BASE TEÓRICA PARA REESTRUTURAÇÃO ACADÊMICA E PARA A FORMAÇÃO PEDAGÓGICA}

\subsection{Os princípios para organização curricular em cursos de graduação da Universidade de Caxias do Sull $^{1}$ (UCS)}

Antes de definir princípios a serem observados para a organização curricular em cursos de graduação na UCS, foram definidos referenciais orientadores da reflexão tanto para a (re)estruturação dos cursos vigentes quanto para a proposta de novos cursos na Instituição. São eles: 1) a graduação como etapa inicial da educação profissional permanente; 2) o curso como formação para determinado campo de atuação profissional (e não apenas para o mercado de trabalho); 3) a consciência das implicações éticas da atuação profissional; 4) o Projeto de Curso como "processo" e como construção coletiva; 5) o Projeto de Curso como instrumento de gestão, de qualificação e de acompanhamento do processo de formação do aluno; 6) a sustentabilidade econômica como integrante do projeto de curso; 7) a inserção internacional do ensino de graduação como imperativo à qualidade.

\footnotetext{
1 Definições e esclarecimentos sobre a política curricular dos cursos de graduação da Universidade de Caxias do Sul podem ser obtidos em: STEDILE e cols. Cadernos da UCS/Graduação. EDUCS, 2008.
} 
Os princípios definidos como subsídios para a tomada de decisões quanto ao "que" e "como" organizar os currículos em uma universidade precisam ser revistos e redefinidos sempre que necessário tendo presente os novos e dinâmicos desafios da sociedade contemporânea. Para a UCS foram definidos três princípios: a interdisciplinaridade, a

\section{flexibilidade curricular e a não especialização.}

A interdisciplinaridade é entendida como a possibilidade de interação de diferentes perspectivas na formulação e busca de solução diante de um mesmo problema por meio da integração de conhecimentos de diferentes áreas no trabalho relativo a essa solução. Nesse sentido, constitui-se em um princípio orientador que não somente dá unidade ao conhecimento, mas que também serve como um elemento epistemológico indispensável para evitar a elaboração de um currículo fragmentado e superpovoado de disciplinas, as quais nem sequer são devida e suficientemente articuladas ou integradas entre si. Esse princípio, ao ser considerado para a organização curricular, implica mudanças nas práticas docentes e discentes, pois se torna imprescindível assumir em definitivo que a maioria dos problemas sociais não se resolve por conhecimentos afetos a uma única área de conhecimento.

Outro aspecto a considerar quanto à interdisciplinaridade é que ela não pode ser resumida apenas como a capacidade individual de integrar diferentes áreas do conhecimento, mas também como capacidade de construir coletivamente respostas aos problemas. Pressupõe, portanto, a relação interpessoal e interprofissional, o respeito às diferentes formas de ver o mundo e também a capacidade de reflexão sobre como, quanto e em que grau integrar os conhecimentos das diferentes áreas.

A flexibilidade refere-se a importância de o aluno tomar decisões sobre sua própria trajetória de formação profisssional e cidadã, ao mesmo tempo em que direciona os currículos dos vários cursos para uma integração e uma interlocução permanentes. Nessa direção, a estrutura curricular não deve ser compreendida como forma ou formas, mas deve assumir a diversidade de experiências como princípio de realidade, potencializando as conexões sociopolíticas e profissionais do processo formativo. Abrange também diferentes formas de trabalhar os conteúdos e o avanço do conceito de currículos disciplinares para outras formas de organização, buscando que o processo de construção do conhecimento alcance níveis cada vez mais elevados de complexidade e inter-relação. Dessa forma, colabora no sentido de superar o conceito de aprendizagem linear, cumulativa e isolada. Manifesta-se, por exemplo, na especificação de pré-requisitos como elementos orientadores, na disponibilização de múltiplas formas de aprendizagem e de formação, na ampliação da oferta de opções de 
matrícula, na disponibilização de oportunidades de alunos de determinadas áreas buscarem o desenvolvimento de habilidades em áreas até então percebidas como "incomunicáveis".

A não-especialização é um princípio que tem subsidiado pensar os currículos de graduação como uma etapa inicial da formação profissional permanente. A preocupação básica desse princípio é a de selecionar conteúdos e experiência que permitem ao aluno construir e desenvolver significados a partir de um conhecimento essencial e sólido. Deles não se espera, portanto, uma formação já especializada, mas o desenvolvimento de competências e habilidades que possam servir como elemento de fundamentação adequada tanto para as futuras atividades profissionais, quanto para a criação de uma concepção de mundo diferenciada. Nesse sentido, os cursos de graduação não têm como objetivo a formação de especialistas, mas sim o desenvolvimento de sólida formação geral, básica e específica de cada área, indispensável para o exercício profissional e para a realização futura de estudos em nível avançado e especializado.

Do conjunto de princípios e referenciais foi possível definir o entendimento do que se ocupa a formação profissional em nível superior, conforme apresentado no Quadro 1 que mostra que a formação profissional engloba a formação geral, específica (básica e própria de cada profissão) e complementar. Para uma formação profissional adequada, qualquer uma dessas dimensões são importantes, indispensáveis e complementares e dão conta da multidimensionalidade da formação profissional.

Para a formação geral foram definidas cinco disciplinas comuns a todos os cursos, sendo a formação nesta dimensão complementada de acordo com as especificidades dos mesmos. Essas disciplinas têm a função de aumentar a capacidade reflexiva do aluno sobre seu papel como futuro profissional egresso do nível superior, sobre a inserção do seu trabalho na sociedade, além de colaborar na identificação de diferenciais de habilidades e competências que caracterizam o profissional egresso da UCS.

Nessa linha de referenciais e princípios, a Universidade tomou medidas gerais importantes, tais como: definição de disciplinas de formação comum; definição de disciplinas de formação geral e básica por área do conhecimento; transformação dos pré-requisitos existentes em orientativos e manutenção daqueles que necessariamente se constituem prérequisitos; limitação de proposição de disciplinas eletivas por cursos e estímulo à oferta por área de conhecimento; revisão dos “modelos” de estruturação dos projetos de curso. 


\begin{tabular}{|c|c|c|}
\hline \multicolumn{3}{|c|}{ FORMAÇÃO PROFISSIONAL EM NÍVEL DE GRADUAÇÃO } \\
\hline FORMAÇÃO GERAL & \multicolumn{2}{|c|}{$\begin{array}{l}\text { Refere-se ao desenvolvimento de competências que atendam à } \\
\text { multidimensionalidade da educação superior. }\end{array}$} \\
\hline $\begin{array}{l}\text { FORMAÇÃO } \\
\text { ESPECÍFICA }\end{array}$ & $\begin{array}{l}\text { BÁSICA } \\
\text { (PARTILHÁVEL POR } \\
\text { ÁREAS DE } \\
\text { CONHECIMENTO) }\end{array}$ & $\begin{array}{l}\text { Refere-se ao desenvolvimento de } \\
\text { competências que capacitam o entendimento } \\
\text { dos instrumentos e conceitos fundamentais } \\
\text { pertinentes a um determinado campo de } \\
\text { atuação profissional, partilhadas por áreas de } \\
\text { conhecimento. }\end{array}$ \\
\hline & $\begin{array}{l}\text { PRÓPRIA } \\
\text { DA PROFISSÃO }\end{array}$ & $\begin{array}{l}\text { Refere-se ao desenvolvimento de } \\
\text { competências que definem e caracterizam um } \\
\text { campo de atuação profissional específico. }\end{array}$ \\
\hline $\begin{array}{l}\text { FORMAÇÃO } \\
\text { COMPLEMENTAR } \\
\text { (Flexível) }\end{array}$ & \multicolumn{2}{|c|}{$\begin{array}{l}\text { Refere-se ao desenvolvimento de competências por livre escolha do } \\
\text { estudante de graduação, podendo ter ou não relação direta com o campo } \\
\text { de atuação profissional específico. }\end{array}$} \\
\hline
\end{tabular}

QUADRO 1 Formação profissional em nível superior (UCS-2008).

Para atingir esse objetivo, muito mais do que elaborar e apresentar uma proposta formal de trabalho (projeto de disciplina) para cada uma dessas Unidades de Aprendizagem é indispensável a capacitação pedagógica dos professores. Tal capacitação pretende transformar em condutas profissionais docentes os conhecimentos que a pedagogia, a didática, a neurociência e a psicologia disponibilizam sobre como se aprende e apreende conhecimentos. Significa que para que essas Unidades de Aprendizagem possam de fato cumprir com o seu papel na formação profissional é necessário construir ambientes de aprendizagem em uma lógica diferente da tradicional.

\subsection{A formação de professores para atuar em nível superior de ensino tendo por base a} proposta curricular dos cursos de graduação

A profissionalização do professor tem sido um assunto que pode ser destacado como um dos mais importantes para a qualificação dos processos de ensinar e aprender em nível superior. Essa profissionalização passa necessariamente pela capacitação pedagógica dos professores, uma vez que, para constituir as universidades brasileiras, eram escolhidos profissionais com atuação destacada em suas áreas de conhecimento, sem ênfase à sua capacidade de atuação como docente, ou, como tem sido repetido insistentemente (e equivocadamente) por professores e alunos, sem "capacidade didática" para "passar os conteúdos". 
A retrospectiva histórica sobre a profissionalização do professor, apontada por Behrens (1996), Ballenilla (1995), Demo (1993), Porlán e Martín (1997), Vasconcellos (1995), Perrenoud (2001), Masetto (2003), mostra um paradigma de reprodução e repetição das propostas de formação dos professores que atuaram na formação desses profissionais/professores; um estigma de que para ser docente basta ser um bom profissional em uma área de atuação; uma dinâmica fundamentada na transmissão verbal de conteúdos sem conexão direta com a realidade e organizados de maneira acumulativa e disciplinar; um modelo de formação pedagógica academicista e utilitarista; uma percepção do conhecimento como um processo cumulativo de verdades. Essas características limitavam o fazer docente à forma como o conhecimento deveria ser organizado para ser apresentado aos alunos.

Pouco ou quase nada de atenção era dada ao que acontecia com o aluno enquanto o professor professava seus conhecimentos. Tampouco o professor sentia-se responsável pelo insucesso daquele que não conseguia acompanhar sua forma de entender os fenômenos. Centrar e concentrar a atenção do professor sobre a aprendizagem, mesmo que pareça algo fácil e lógico, talvez seja o grande desafio de superação paradigmática do meio acadêmico. Isso porque exige do professor uma nova lógica de pensamento e de organização, que considera o aluno como sujeito ativo do processo e capaz de desenvolver autonomia de aprendizagem (CORTELETTI, RIBEIRO E STEDILE, 2002).

Para Masetto (2003), é possível perceber mudanças no ensino superior em quatro pontos: 1) no processo de ensino; 2) no incentivo à pesquisa; 3) na parceria e co-participação entre professor e aluno no processo de aprendizagem; e 4) no perfil docente. Em relação a esse último aspecto é fundamental pensar no desenvolvimento das competências básicas e necessárias para se realizar a docência e, no nível superior, além da exigência em ser competente em determinada área de conhecimento, a docência exige do professor domínio na área pedagógica.

A formação do professor necessita ser ancorada em um novo paradigma de ciência, conhecimento e mundo, diferenciado daquele que tem marcado a prática universitária. Significa que essa nova formação precisa considerar a ciência como um ato humano, historicamente situado. O conhecimento, produto desse sistema complexo, deve ser entendido como um fenômeno cultural, como uma produção social que nasce num espaço e num tempo em função dos desafios sociocognitivos de um contexto. É uma construção social que se realiza mediante o debate e a troca de idéias. Moraes (2000), ao tratar da reintegração do sujeito como uma das implicações do novo paradigma educacional explicita que o 
conhecimento decorre de uma relação indissociável entre sujeito observador, objeto observável e processo de observação, reconhecendo que o indivíduo participa da construção do conhecimento não apenas com o uso predominante do raciocínio e da percepção do mundo exterior pelos sentidos, mas também usando as sensações, os sentimentos, as emoções e a intuição para aprender. Nesse pensamento, o mundo é concebido, conforme Capra (1996), como um todo integrado, como uma rede de fenômenos que estão fundamentalmente interconectados, interdependentes.

Tornar claras essas concepções é imprescindível visto que a concepção de conhecimento acompanha a definição da prática pedagógica a ser desenvolvida, e o ensinar e o aprender estão alicerçados numa concepção de mundo e de ciência. Nesse contexto, as competências necessárias ao professor parecem apontar para a necessidade de inserir a formação pedagógica dentro de um referencial de permanente reflexão crítica, no qual o fazer pedagógico seja fonte de dados para desenvolver pesquisas que subsidiem a tomada de decisões sobre o que, como e quanto ensinar e aprender no mundo em permanente mudança.

Perrenoud (2000) apresenta um referencial de competências para orientar os programas de formação do professor, que representa um fio condutor que contribui para redelinear a atividade docente e sua evolução. As competências apontadas são julgadas prioritárias pelo autor por duas razões fundamentais: 1) por serem coerentes com o novo enfoque da formação contínua dos professores, cuja meta é antes fazer aprender do que ensinar; 2) por serem compatíveis com os eixos da mudança de renovação da escola (ciclos de aprendizagem, focalização sobre o aluno, avaliação formativa, métodos ativos, trabalhos por situações-problemas, procedimentos de projetos, desenvolvimento de competências, transferência de conhecimentos).

A busca de uma pratica pedagógica competente, de um ensino de melhor qualidade, de novas alternativas para a docência no ensino universitário, de caminhos que levam à construção e produção de conhecimentos que ultrapassem a arrogância do conhecimento cristalizado e a efetivação de experiências que busquem a criação de novas formas de ensino e pesquisa são desafios que a exigência da modernidade está requerendo das universidades que têm mantido como objetivos centrais a produção de conhecimentos e a formação técnica e científica e como objetivo apenas secundário a formação de professores. 


\section{METODOLOGIA DO TRABALHO}

\subsection{Contexto de desenvolvimento da capacitação pedagógica}

A UCS desenvolve desde 1996 um programa de capacitação pedagógica dos docentes. Este programa é desenvolvido tendo por base dois pressupostos básicos: (a) a formação do professor precisa ser contínua e em serviços; (b) a reflexão sobre a ação é uma estratégia importante em um processo de formação permanente em serviço (CORTELETTI, RIBEIRO E STEDILE, 2002).

A tríade ação-reflexão-ação é essencial na busca da educação continuada e necessária ao profissional que acredita ser a educação um caminho para a transformação social, visto que coloca o próprio fazer profissional docente como objeto de análise com vistas ao aprimoramento do fazer, enquanto este fazer se efetiva. Schön, citado por Garcia (1992), ao propor o conceito de reflexão-na-ação, o define como um processo mediante o qual os professores aprendem a partir da análise e interpretação da sua própria atividade. Essa definição parece ter relação direta com uma característica fundamental do ensino: é uma profissão em que a própria prática conduz à criação de um conhecimento específico ligado à ação e que só pode ser adquirido por meio do contato com a prática. Assim, a prática, enquanto objeto de reflexão, constitui-se numa fonte de conhecimento por possibilitar ao professor construir uma teoria que a explique.

Nesse sentido, a formação, para ser eficaz, precisa ser contínua, centrada na atividade da sala de aula, valorizando a prática, a ação, o pensamento reflexivo, a crítica, a experimentação, a coleta de dados, a sistematização de novos conhecimentos e o aprimoramento da ação. É uma formação na qual se destaca o valor da prática como elemento de análise e reflexão do professor.

Em outras palavras, o fazer do professor é transformado em objeto de estudo e possibilita o aprimoramento das competências para a docência em nível superior. O processo permite ao professor refletir para a ação docente (planejar); na ação (orientar seu fazer e adequá-lo enquanto o processo de aprendizagem está transcorrendo); e sobre a ação (avaliar).

Essa capacitação pedagógica precisa ser melhor planejada quando a unidade de aprendizagem a que o professor deve tornar-se capaz está relacionada à formação comum dos alunos de uma instituição. Isso porque as disciplinas de formação comum são responsáveis pelo desenvolvimento de habilidades e competências que devem imprimir as características definidoras de um perfil profissional do egresso daquela instituição. No caso da UCS, foram 
definidas cinco unidades de aprendizagem (disciplinas) de formação comum a todos os cursos de graduação: Leitura e Escrita na Formação Universitária; Universidade e Sociedade; Ética; Epistemologia; e Seminários de Pesquisa, com número significativos de professores atuando, para os quais não basta apresentar o programa de trabalho a ser seguido. É necessário que eles tenham um profundo conhecimento e entendimento da função da Unidade de Aprendizagem no processo de formação profissional e um entendimento da relação entre as Unidades de Aprendizagem propostas e o perfil de egresso da Instituição.

Pela complexidade do tema e número de envolvidos no processo, para os fins desse trabalho, será apresentado o modelo pedagógico de formação docente para as disciplinas Universidade e Sociedade e Leitura e Escrita na formação Universitária, as quais foram implementadas no ano de 2009.

\subsection{O modelo pedagógico adotado na capacitação}

O processo iniciou pela inscrição dos interessados, via site UCS. No primeiro encontro foram apresentados os princípios e diretrizes da organização curricular para os cursos de graduação da UCS, bem como a função de cada disciplina no contexto da formação profissional. Na sequência, cada professor foi convidado a escrever sobre duas questões básicas: (1) O que me traz a esta experiência? e (2) O que eu trago a esta experiência? Essas questões possibilitaram perceber as motivações e os conhecimentos prévios dos professores.

A partir desse momento, em encontros quinzenais de duas horas, iniciou-se um processo coletivo de construção do projeto de cada uma das unidades de aprendizagem, por meio da discussão dos seguintes elementos constitutivos: ementa, objetivos de aprendizagem, conteúdos, metodologia, avaliação e bibliografia (básica e complementar). A culminância do trabalho se deu por meio de imersões para concluir o trabalho e para aprofundamento teórico tanto dos saberes docentes, quanto dos conteúdos a serem trabalhados com os alunos. Também fez parte das interações um AVA especialmente construído para cada unidade de aprendizagem que serviu para a participação e compartilhamento de materiais e conhecimentos de forma permanente. Foram utilizadas em média 80 horas de trabalho coletivo para cada unidade de aprendizagem. O princípio pedagógico básico para a construção das aprendizagens foi o interacionista, segundo o qual, no processo de interação com o conhecimento já estruturado e com os pares é possível (re) significar e (re) construir os saberes docentes. Também foi partilhada a percepção de que a construção coletiva permite um 
crescimento também coletivo e aumenta a probabilidade de que o produto produzido, em termos de proposta de trabalho com os alunos, seja aprimorada.

O trabalho se desenvolveu em duas fases:

a) elaboração do Projeto de Trabalho da Unidade de Aprendizagem: encontros quinzenais e uma imersão ao final do semestre, intercalados por discussões no AVA. Além disso, foram convidados palestrantes para discutir assuntos de interesse comum (A neurociência e a aprendizagem; e Como acessar conhecimentos prévios dos alunos);

b) implementação da proposta: encontros mensais de avaliação e acompanhamento ao longo do processo de operacionalização da proposta, com interações permanentes via AVA e imersão ao final do semestre para avaliação, atualização e aprimoramento do projeto, a partir da vivência do semestre. Para fins de análise e tabulação de dados, foram considerados como participantes efetivos apenas aqueles professores que obtiveram $75 \%$ de presenças nos encontros e na imersão.

\section{RESULTADOS OBTIDOS NO DESENVOLVIMENTO DO PROCESSO DE CAPACITAÇÃO}

O número total de professores participantes (156) mostra o possível impacto da ação, uma vez que esses professores, no geral, ministram 3 a 5 disciplinas e há uma probabilidade de que as habilidades pedagógicas desenvolvidas na capacitação sejam utilizadas em outras e diversas disciplinas. Disso decorre uma probabilidade maior de melhorar a qualidade do fazer docente na Instituição.

\begin{tabular}{|l|c|c|c|c|}
\hline \multicolumn{1}{|c|}{ Unidade de Aprendizagem } & $\begin{array}{c}\text { Número de } \\
\text { Encontros 1a } \\
\text { fase }\end{array}$ & $\begin{array}{c}\text { Número de } \\
\text { Encontros 2 } \\
\text { fase }\end{array}$ & $\begin{array}{c}\text { Número de } \\
\text { professores } \\
\text { participantes 1 } \\
\text { fase }\end{array}$ & $\begin{array}{c}\text { Número de } \\
\text { professores } \\
\text { participantes 2 } \\
\text { fase }\end{array}$ \\
\hline 1 - Universidade e Sociedade & 11 & 8 & 30 & 26 \\
\hline 2 - Leitura e Escrita & 11 & 5 & 41 & 35 \\
\hline 3 -Seminário de Pesquisa & 8 & - & 33 & 30 \\
\hline 5 - Epistemologia & 7 & - & 26 & 24 \\
\hline 6 - Ética & 8 & - & 26 & 24 \\
\hline
\end{tabular}

QUADRO 2 Unidades de Aprendizagem, número de encontros e respectivos participantes do processo de capacitação pedagógica

Considerando que a maior parte dos participantes possui titulação obtida em cursos de Pós-Graduação Stricto sensu (94\%) e que, na unidade de aprendizagem "Seminário de Pesquisa", há o maior número de professores doutores do que de mestres, é possível afirmar que a UCS superou a falácia de que para ser um bom professor basta ter um título de mestre ou doutor. Provavelmente o trabalho do Núcleo de Pedagogia Universitária contribuiu para a 
superação dessa idéia e para a consolidação da percepção defendida por Tardif de que o saber do professor é específico e se constrói, se constitui e se aperfeiçoa na prática.

No Quadro 3, vê-se a titulação e regime de trabalho dos docente participantes.

\begin{tabular}{|l|c|c|c|c|c|c|c|c|}
\hline \multirow{2}{*}{ Unidades de disciplinas } & \multicolumn{4}{|c|}{ Regime de Trabalho } & \multicolumn{4}{c|}{ Titulação dos Professores } \\
\cline { 2 - 10 } & Horista & TI & Total & Esp. & Ms & Dr & Pós & Total \\
\hline 1 - Universidade e Sociedade & 22 & 08 & $\mathbf{3 0}$ & 22 & 08 & 30 & 22 & $\mathbf{0 8}$ \\
\hline 2 - Leitura e Escrita & 21 & 20 & $\mathbf{4 1}$ & 21 & 20 & 41 & 21 & $\mathbf{2 0}$ \\
\hline 3 - Epistemologia & 15 & 18 & $\mathbf{3 3}$ & 15 & 18 & 33 & 15 & $\mathbf{1 8}$ \\
\hline 4 - Ética & 19 & 07 & $\mathbf{2 6}$ & 19 & 07 & 26 & 19 & $\mathbf{0 7}$ \\
\hline 5 - Seminários de Pesquisa & 17 & 09 & $\mathbf{2 6}$ & 17 & 09 & 26 & 17 & $\mathbf{0 9}$ \\
\hline
\end{tabular}

QUADRO 3 Titulação e regime de trabalho dos docentes participantes da capacitação, por unidade de aprendizagem.

A maior parte dos professores participantes das Unidades de Aprendizagem "Leitura e Escrita na Formação Universitária" e "Seminários de Pesquisa" são professores de tempo integral. No geral, considerando todos os participantes, havia $40 \%$ de professores de TI. O envolvimento de professores de TI é um elemento importante por oferecer maior estabilidade e continuidade ao processo. Por outro lado, o fato de um grande número de horistas optarem por participar do processo indica um grau de comprometimento com a Instituição e um desejo pessoal de buscar aprimoramento pedagógico.

\subsection{Aspectos observados durante a construção coletiva das Unidades de Aprendizagem "Leitura e Escrita na Formação Universitária (LE) e Universidade e Sociedade (US)}

A capacitação pedagógica foi iniciada com uma técnica de conhecimento do grupo e de reflexão sobre o processo, além da apresentação dos princípios norteadores da política curricular que estava sendo implementada, bem como da função de cada unidade de aprendizagem no processo de desenvolvimento das habilidades e competências que constituem o perfil do egresso da UCS.

Esse momento inicial foi decisivo para o entendimento da tarefa a ser executada, bem como sobre a importância de cada unidade de aprendizagem no sucesso ou insucesso da nova política curricular. Cabe destacar ainda que a percepção do conjunto de unidades de aprendizagem de formação comum favorece a tomada de decisões sobre como conduzir o ambiente de aprendizagem e sobre o grau de clareza quanto às particularidades de cada uma.

Para desencadear a reflexão, cada professor foi convidado a responder por escrito e depois socializar duas questões: 1) O que me traz ao processo; e 2) O que eu trago ao processo, cujos resultados estão apresentados nos Quadros 4 e 5. As razões apresentadas pelos 
professores parecem apontar para um desejo forte de aprender mais sobre a docência (itens 1, $5,6,8,18$ e 19). No geral, os professores percebem que apenas os conhecimentos de sua área de formação, mesmo que indispensáveis, não são suficientes para um fazer pedagógico que favoreça e potencialize a capacidade de aprendizagem dos alunos.

Há também um nítido desejo de superar as práticas tradicionais de ensino, uma vez que transmitir os conhecimentos, especialmente neste momento histórico em que as tecnologias da informação invadem o cotidiano e influenciam nos processos neurofisiológicos de aprender e apreender informações, já não dá conta das necessidades dos acadêmicos.

\begin{tabular}{|c|c|c|c|}
\hline & O que me traz ao processo & LE(40) & US(30) \\
\hline 1. & Interesse em ensinar & 22 & 18 \\
\hline 2. & Participar de um processo novo em que acredito & 25 & 15 \\
\hline 3. & Preocupação em contribuir & 12 & 10 \\
\hline 4. & $\begin{array}{l}\text { Interesse em colaborar com a Instituição nesse momento de } \\
\text { mudanças }\end{array}$ & 8 & 3 \\
\hline 5. & Perspectiva de entender o processo educativo & 5 & 7 \\
\hline 6. & Profissionalização/ qualificação como professor & 15 & 12 \\
\hline 7. & Interesse pela área e pelo tema (Universidade e Sociedade) & - & 8 \\
\hline 8. & Oportunidade de diversificar e aprimorar o fazer pedagógico & 14 & 10 \\
\hline 9. & Ampliar, atualizar e aprofundar conhecimentos & 6 & 17 \\
\hline 10. & Oportunidade de inserção acadêmica & 4 & 8 \\
\hline 11. & Interação com professores de outras áreas e colegas & 7 & - \\
\hline 12. & Construção de posicionamento crítico & - & 9 \\
\hline 13. & Valorização da formação humana e reflexiva na Universidade & 2 & 9 \\
\hline 14. & Paixão pela docência & 2 & 3 \\
\hline 15. & Oportunidade de ficar a par das mudanças e exigências da sociedade & - & 8 \\
\hline 16. & Desafio de aprender & 1 & 3 \\
\hline 17. & Curiosidade & 1 & 4 \\
\hline 18. & Aprender práticas curriculares inovadoras & 4 & 7 \\
\hline 19. & Participar do processo de (re)significação da disciplina & 3 & 13 \\
\hline
\end{tabular}

QUADRO 4 Razões que levaram os professores a participar da capacitação

Outra forte motivação diz respeito à necessidade de buscar novos conhecimentos e ampliar as habilidades para ensinar. Há nas falas dos professores uma nítida clareza de que o que constitui um bom professor é o equilíbrio entre o saber técnico científico e o saber pedagógico.

Em todo o processo de construção coletiva de aprendizagem é necessário haver espaço para que o saber de cada professor, construído pela experiência, seja colocado a serviço da aprendizagem de todos. Nesse sentido, as respostas à questão apresentada no Quadro 5 além de levantar conhecimentos prévios, mostra ao professor que todos têm saberes pedagógicos importantes e que devem ser valorizados. Este Quadro permite perceber que o professor reconhece que um dos maiores legados que traz para um processo como esse são os saberes 
da experiência, conforme o que apresenta Tardif (2000). Muitos professores não se dão conta que sua forma de atuar está ligada a um modelo pedagógico e epistemológico de referência e, se ele não o tornar consciente, terá baixa probabilidade de (re) significar o seu fazer pedagógico. Muitos professores também destacam seu desejo de contribuir e ampliar conhecimentos pedagógicos. Tal como ocorre com os alunos, o conhecimento pedagógico só pode ser construído a partir do desejo e decisão pessoal e depende de motivação e comprometimento de cada um.

\begin{tabular}{|l|c|c|}
\hline \multicolumn{1}{|c|}{ O que trago ao processo } & LE (40) & US (30) \\
\hline - Conhecimento e vivência & 33 & 28 \\
- Disposição e desejo de aprendizagem & 20 & 13 \\
- Curiosidade & 1 & - \\
- Vontade de contribuir & 17 & 8 \\
- Disposição para uma discussão coletiva e interdisciplinar & 3 & 19 \\
- Formação na área e atualização permanente & 6 & 20 \\
- Habilidade de trabalhar em equipe & 1 & - \\
- Conhecimentos sobre AVA, objetos de aprendizagem mediados pela & 2 & 3 \\
- tecnologia & 5 & - \\
- Inquisasações & 1 & - \\
\hline
\end{tabular}

QUADRO 5 Saberes que os professores trazem ao processo de capacitação pedagógica

A partir desse primeiro encontro, foram apresentadas perguntas norteadoras de cada etapa de construção da proposta, iniciando pelos objetivos de aprendizagem. Fundamentalmente, os professores deveriam pensar sobre a seguinte questão: Que aprendizagens os acadêmicos precisam desenvolver ao longo dessa disciplina? Esse foi o primeiro grande desafio, uma vez que a maior parte dos professores está habituado a iniciar o processo definindo os conteúdos necessários e não as aprendizagens a serem desenvolvidas. Somente após obter certo consenso sobre as aprendizagens é que as demais questões foram postas: Que conteúdos podem favorecer o desenvolvimento de tais aprendizagens? Que estratégias metodológicas podem maximizar o processo de aprender e a autonomia do aluno? Como acompanhar o processo de aprendizagem? Que instrumentos de avaliação são úteis nessa situação e ambiente de aprendizagem? Que bibliografia básica e complementar pode ser indicada?

Cada uma dessas questões foi trabalhada de forma sequencial, sem perder de vista as aprendizagens definidas para a unidade de aprendizagem em questão, retornando, porém, às questões anteriores sempre que necessário. Quando da definição dos conteúdos, houve uma socialização de autores, fontes e recursos importantes para definições conceituais. Durante as 
discussões sobre os princípios que deveriam nortear a definição quanto à metodologia, foram socializadas diferentes formas e possibilidades de trabalho. A questão da avaliação também foi objeto de intensa discussão, uma vez que esta é uma dificuldade presente na maior parte das discussões pedagógicas dos professores em qualquer nível de ensino.

Emergiu também a necessidade de conhecimentos sobre como os alunos aprendem. Para suprir essa necessidade foram chamados dois especialistas para discutir conhecimentos sobre"Neurociência e Aprendizagem" e "Como acessar os conhecimentos prévios dos alunos".

É importante salientar que a aprendizagem foi balizadora da reflexão pedagógica e que este é um avanço na forma de pensar um ambiente de aprendizagem uma vez que coloca as necessidades de aprendizagem do aluno como centro das atenções do professor e orienta o processo de decisões pedagógicas a partir do que é importante aprender.

A síntese das decisões sobre as aprendizagens a serem desenvolvidas estão resumidamente apresentadas no Quadros 6.

\begin{tabular}{|c|c|}
\hline Leitura e Escrita na Formação Universitária & Universidade e Sociedade \\
\hline $\begin{array}{l}1 \text { - ( Re) Construir o contexto situacional tanto na leitura quanto } \\
\text { na produção: quem escreve, para que(m) escreve, qual sua } \\
\text { função social, cultural, histórica, política, em qual meio circula } \\
\text { o texto. } \\
2 \text { - Estabelecer e identificar a interação entre leitor-autor-texto } \\
\text { nos seus respectivos contextos de produção. } \\
3 \text { - Localizar informações pontuais a partir de objetivos } \\
\text { definidos. } \\
4 \text { - Distinguir informações principais e secundárias, implícitas e } \\
\text { explícitas, de acordo com objetivos pré-definidos. } \\
5 \text { - Analisar o processo argumentativo em textos multimodais: } \\
\text { 1. estabelecendo relações, comparações (semelhanças } \\
\quad \text { e contrastes) em diferentes situações; } \\
\text { 2. detectando contradições; } \\
\text { 3. reconhecendo a repercussão das escolhas } \\
\quad \text { linguísticas realizadas; } \\
\text { 4. extraindo conclusões por dedução ou indução; } \\
\text { 5. identificando tese, argumentos e evidências; } \\
\text { 6. criticando dados apresentados. } \\
6 \text { - Selecionar fontes confiáveis de informação. } \\
7 \text { - Reconhecer a presença de intertextualidade e } \\
\text { interdiscursividade como formadora de sentido em textos; } \\
8 \text { - Articular diferentes vozes com a citação e referenciação } \\
\text { adequada das fontes. } \\
9 \text { - Elaborar a síntese reconstrutiva do texto lido. }\end{array}$ & $\begin{array}{l}1 \text { - Identificar dimensões históricas, } \\
\text { sociais, econômicas, políticas, } \\
\text { culturais e ambientais que permitem } \\
\text { interpretar relações entre sociedade, } \\
\text { Estado e cultura } \\
2 \text { - Compreender relações entre } \\
\text { sociedade, Estado e cultura a partir } \\
\text { da análise histórico-crítica de } \\
\text { processos econômicos, políticos, } \\
\text { sociais, culturais e ambientais. }\end{array}$ \\
\hline
\end{tabular}


10 - Planejar, monitorar e avaliar o processo de produção e revisão textual.

11 - Utilizar adequadamente os recursos linguísticos e textuais atinentes ao gênero objeto de estudo.

12 - Planejar e realizar exposições orais.

QUADRO 6 Objetivos de aprendizagem propostos

A análise das aprendizagens propostas está escrita de forma a deixar claro para alunos e professores o que deverá ser aprendido e ensinado ao longo do semestre, ou seja, orientam o aluno para suas aprendizagens (permitindo elementos para uma autoavaliação) e orientam o professor quanto ao que deverá ser feito para favorecer que as aprendizagens se efetivem.

Cabe destacar que essas aprendizagens são complexas e, muitas vezes, difíceis de serem desenvolvidas numa única experiência. A clareza sobre as mesmas, no entanto, podem ser decisivas na mobilização de recursos para que o ensino e a aprendizagem ocorram. No caso da Leitura e Escrita, as aprendizagens são mais instrumentais e dependem diretamente dos anos de escolarização anteriores à universidade (conhecimentos prévios) e ajudam o aluno a utilizar a leitura e escrita como instrumentos de aprendizagem. No caso da Universidade e Sociedade, introduzem o aluno nas habilidades de pensamento indispensáveis a um egresso de nível superior para entender a sociedade e inserir seu trabalho com ética e competência na mesma.

A síntese das decisões sobre as estratégias metodológicas e de avaliação a serem desenvolvidas estão resumidamente apresentadas no Quadro 7. Novamente, as decisões sobre o contexto de sala de aula e sobre o acompanhamento em termos de avaliação das aprendizagens deixam clara a intenção dos professores em concentrarem-se no que ocorre com o aluno durante o processo de aprender, ao mesmo tempo em que apresenta o papel do professor e do aluno nesse contexto: o professore orienta o processo, mas as aprendizagens são individuais e construídas por cada aluno ao experenciar situações que permitam elaborar ou reelaborar conceitos e desenvolver novas habilidades e competências, entre as quais as de ler e escrever e de refletir sobre a sociedade, a universidade e sobre seu papel nesse contexto.

Do ponto de vista pedagógico, pode-se dizer que a metodologia da aula é fator importante na construção do ambiente de aprendizagem. Quando o professor tem consciência que o que faz em sala de aula e a qualidade do material disponibilizado aos alunos, entre outras variáveis, podem favorecer ou dificultar a aprendizagem, tem maior probabilidade de selecionar aquilo que, de fato, podem potencializar a aprendizagem. 


\begin{tabular}{|c|c|c|}
\hline $\begin{array}{c}\text { Unidade de } \\
\text { Aprendizagem }\end{array}$ & Estratégias Metodológicas & Estratégias de Avaliação \\
\hline $\begin{array}{c}\text { Leitura e Escrita na } \\
\text { Formação } \\
\text { Universitária }\end{array}$ & $\begin{array}{l}\text { A disciplina terá como ponto de partida uma } \\
\text { identificação do perfil de leitor e de produtor } \\
\text { de textos, aprendiz nesta disciplina. As } \\
\text { intervenções do professor terão como fim } \\
\text { sensibilizar os acadêmicos para os processos } \\
\text { de interação social por meio da linguagem } \\
\text { escrita e falada, usada não somente no meio } \\
\text { universitário. O professor será orientador da } \\
\text { disciplina e buscará desenvolver com o grupo } \\
\text { uma atitude autônoma de aprendizado, com } \\
\text { base em estratégias de leitura (objetivo, } \\
\text { inferência, conhecimento prévio, relação } \\
\text { entre leitor-autor-texto...) e de produção } \\
\text { (reflexão, planejamento, monitoramento, } \\
\text { revisão para escrita e reescrita) de textos } \\
\text { multimodais. As atividades orientadas } \\
\text { partirão de situações-problema que poderão } \\
\text { culminar em projetos de trabalho. Para isso, } \\
\text { serão utilizados meios diversos, como } \\
\text { trabalhos individuais, ou em pequenos ou } \\
\text { grandes grupos, aulas em laboratório, etc. }\end{array}$ & $\begin{array}{l}\text { O professor acompanhará o } \\
\text { processo de cada aprendiz, } \\
\text { realizando avaliação constante, } \\
\text { buscando (re)direcionar o } \\
\text { trabalho de forma a auxiliar o } \\
\text { acadêmico na superação de suas } \\
\text { dificuldades. Desse modo, serão } \\
\text { desenvolvidos, no mínimo, três } \\
\text { instrumentos de avaliação, com } \\
\text { percentuais crescentes, que } \\
\text { objetivem evidenciar as } \\
\text { aprendizagens efetivadas. }\end{array}$ \\
\hline $\begin{array}{l}\text { Universidade e } \\
\text { Sociedade }\end{array}$ & $\begin{array}{l}\text { A disciplina terá a reflexão como pressuposto } \\
\text { básico de trabalho no cotidiano da sala de } \\
\text { aula, também como forma de motivar a } \\
\text { participação efetiva do aluno e seu } \\
\text { comprometimento com a própria } \\
\text { aprendizagem. O professor, ao orientar o } \\
\text { processo de aprendizagem, buscará } \\
\text { desenvolver com o grupo uma atitude } \\
\text { autônoma. Para tanto, serão desenvolvidas } \\
\text { atividades individuais ou em grupo com } \\
\text { leitura orientada e problematização de textos, } \\
\text { estudos dirigidos e voltadas à realidade, } \\
\text { seminários e, sempre que possível, serão } \\
\text { utilizadas situações-problema, as quais } \\
\text { exijam fundamentos teóricos para sua } \\
\text { resolução. }\end{array}$ & $\begin{array}{l}\text { A avaliação será sistemática e } \\
\text { constante, valorizando a } \\
\text { participação, comprometimento } \\
\text { e frequência do aluno. Serão } \\
\text { utilizados três Instrumentos de } \\
\text { avaliação, sendo, no mínimo, } \\
\text { uma individual por escrito. } \\
\text { Também serão avaliadas as } \\
\text { diferentes atividades (trabalho } \\
\text { de grupo ou individuais), } \\
\text { juntamente com o seminário } \\
\text { final ou trabalho final voltado a } \\
\text { aspectos da realidade. Para fins } \\
\text { de aferição da nota, a } \\
\text { composição final será somativa, } \\
\text { observando-se uma distribuição } \\
\text { equitativa entre os diferentes } \\
\text { instrumentos de avaliação. Os } \\
\text { trabalhos realizados ao longo do } \\
\text { semestre em sala de aula não são } \\
\text { recuperáveis. }\end{array}$ \\
\hline
\end{tabular}

QUADRO 7 Estratégias metodológicas propostas

\subsection{Dificuldades e resistências encontradas}

Desenvolver um processo de construção coletiva de disciplinas comuns aos cursos de graduação para atingir 32 mil alunos não é uma tarefa pouco complexa. Muitas dificuldades 
foram encontradas, as quais são destacadas, de acordo com a avaliação dos professores, ao término do processo:

(a) ter como ponto de partida outros referenciais que não os conteúdos: a lógica de organização ainda predominante nos diferentes níveis de ensino é a lógica dos conteúdos. Projetos de curso são pensados a partir de disciplinas e não das necessidades da sociedade em relação ao trabalho desses futuros profissionais. Os professores também, não raramente, ao iniciarem seu planejamento, têm como ponto de partida os conteúdos a serem trabalhados, dando, muitas vezes, preferência por aqueles que lhe são familiares ou que "domina", sem considerar quais desses conteúdos são importantes e que aprendizagens devem ser desenvolvidas tendo os conteúdos como meio para tal. Nessa experiência, não foi diferente: a expectativa era definir de imediato os conteúdos a serem trabalhados, e a inversão da lógica trouxe resistências de diferentes ordens;

(b) superar os conhecimentos prévios que são obstáculos à construção do novo: os estudiosos de pedagogia são praticamente unânimes em afirmar que os conhecimentos prévios são indispensáveis à construção de novos conhecimentos. No entanto, quando esses conhecimentos são equivocados ou quando provêm da experiência de muitos anos, é mais difícil modificá-los os transformá-los;

(c) perceber que a competência pedagógica é tão importante quanto a competência em determinada área de conhecimento: a resistência quanto a esse aspecto pode ser entendida a partir da lógica da transmissibilidade das informações. Em geral, o domínio da área pedagógica (profissionalismo docente) é o ponto mais carente dos professores universitários, seja porque nunca tiveram a oportunidade de entrar em contato com essa área, seja porque vêem-na como algo supérfluo ou desnecessário para sua atividade de ensino. (MASETTO, 2003).

\subsection{Avaliação do processo após um semestre de experiencia}

Ao final do semestre de trabalho os professores foram convidados a responder a questões que pudessem trazer elementos importantes em termos de avaliação da experiência. Dez professores da Unidade de Aprendizagem Leitura e Escrita e dez de Universidade e Sociedade responderam ao instrumento cujos dados estão apresentadas nos Quadros 8 e 9. O Quadro 8 deixa claro que houve grande número de estratégias utilizadas pelos professores. $\mathrm{O}$ que é importante destacar, contudo, é que as mesmas remetem para uma atividade do aluno como construtor e responsável pelo seu processo de aprendizagem, tais como a 2, 3, 5, 6, 7, 8, $9,10,12,13,16,17,18$.

Entre as dificuldades apontadas é importante destacar a questão da organização do tempo. Segundo o referencial da teoria Metacognitiva, ao tomar consciência sobre a necessidade de organizar o tempo disponível para obtenção de fins cognitivos, o professor pode empreender estratégias que facilitam a obtenção do mesmo (no caso a aprendizagem). 


\begin{tabular}{|c|c|}
\hline \multicolumn{2}{|c|}{ Leitura e escrita na formação universitária ( 10 respondentes) } \\
\hline Estratégias desenvolvidas & Dificuldades enfrentadas \\
\hline $\begin{array}{l}\text { 1- Utilização de diferentes recursos didáticos (filmes, } \\
\text { laboratório de informática, AVA). } \\
\text { 2- Diálogo constante sobre o papel do aluno em sua } \\
\text { própria formação. } \\
\text { 3- Uso de textos interessantes e mobilizadores da } \\
\text { discussão. } \\
\text { 4- Uso das tecnologias da informação. } \\
\text { 5- Trabalho de exploração de textos com questões de } \\
\text { interpretação, análise e compreensão. } \\
\text { 6- Estímulo a produção textual dos alunos. } \\
\text { 7- Discussões e trabalhos com temáticas selecionadas } \\
\text { pelos próprios alunos. } \\
\text { 8- Produção de texto autobiográfico. } \\
\text { 9- Análise de textos com relação aos aspectos de } \\
\text { coerência e coesão. } \\
\text { 10- Produção de resenha temática com reescrita. } \\
\text { 11- Utilização de cartas dos leitores enviadas a jornais ou } \\
\text { revistas. } \\
\text { 12- Produção e reescrita de resenhas temáticas. } \\
\text { 13- Pesquisa de temas em fontes confiáveis. } \\
\text { 14- Leituras relacionadas a área de formação. } \\
\text { 15- Leituras de obras literárias clássicas. } \\
\text { 16- Juri simulado. } \\
\text { 17- Análise da escrita de emails. } \\
\text { 18- Elaboracão de revista. }\end{array}$ & $\begin{array}{l}\text { 1- } \quad \text { Problemas com o AVA } \\
\text { (operacionalidade) } \\
\text { 2- } \quad \text { Dificuldades dos alunos em } \\
\text { fazer citações. } \\
\text { 3- } \quad \text { Oralidade: pouco tempo para } \\
\text { trabalhar. } \\
\text { 4- } \quad \text { Escolha de gêneros textuais. } \\
5-\quad \text { Organização do tempo. } \\
6-\quad \text { Turmas muito heterogêneas. } \\
7-\quad \text { Definição clara de gêneros } \\
\text { adequados para cursos técnicos. } \\
8-\quad \text { Número de alunos. } \\
9-\quad \text { Seleção de textos. } \\
10-\quad \text { Dificuldades com o AVA. }\end{array}$ \\
\hline
\end{tabular}

QUADRO 8 Estratégias e dificuldades na operacionalização da Unidade de Aprendizagem Leitura e Escrita na Formação Universitária

Cabe destacar ainda que muitas das dificuldades apontadas estão relacionadas às decisões dos próprios docentes, o que é fator indispensável no sentido do desenvolvimento das competências pedagógicas necessárias para a superação das mesmas. Em outras palavras, a consciência da dificuldade aponta para a possibilidade de mobilização do esforço cognitivo necessário ao desenvolvimento da competência pedagógica capaz de superá-la.

Por fim, um comentário ilustra o sentimento expresso por grande número de professores quanto a oportunidade de viver esta experiência:

Gostaria de agradecer a oportunidade de trabalhar com esta disciplina, pois estou certa que contribuir para meu crescimento como professora e como profissional.

Com relação à unidade de aprendizagem Universidade e Sociedade, as estratégias e dificuldades estão apresentadas no Quadro abaixo.

Nessa avaliação, também é clara a preocupação dos professores em superar a lógica da transmissão de informações para uma lógica de participação do aluno no processo de 
aprendizagem. As estratégias metodológicas que foram desenvolvidas apontam para a superação da idéia pré-concebida de que o aluno aprende ouvindo e o professor ensina falando. A interação promovida pela análise do conhecimento já estruturado, mas submetido à discussão e à crítica, possibilita a (re) elaboração e complexificação dos conceitos tidos na mente como conhecimentos prévios.

\begin{tabular}{|c|c|}
\hline \multicolumn{2}{|c|}{ Universidade e Sociedade (10 respondentes) } \\
\hline Estratégias desenvolvidas & Dificuldades enfrentadas \\
\hline $\begin{array}{l}\text { 1- Examinar e discutir sobre o papel da } \\
\text { Universidade e do aluno como futuro } \\
\text { profissional. } \\
\text { 2- Utilização de estudos de caso. } \\
\text { 3- Realização de seminários. } \\
\text { 4- Construção de mapas conceituais } \\
\text { colaborativos. } \\
\text { 5- Utilização das técnicas "colcha de retalhos" } \\
\text { e construção de imagens. } \\
\text { 6- Utilização de trabalhos de sala de aula com } \\
\text { pequenos textos (não apenas o discurso do } \\
\text { professor), para discussão e crítica dos } \\
\text { mesmos. } \\
\text { 7- Incorporação e uso das tecnologias da } \\
\text { informação nas aulas. } \\
\text { 8- Discussão de temas diretamente vinculados à } \\
\text { vida social do aluno. } \\
\text { 9- Problematização de temas para serem } \\
\text { discutidos em pequenos grupos. } \\
\text { 10- Utilização de filmes e documentários. } \\
\text { 11- Utilização de recursos como o mapa mundi, } \\
\text { constituição de 1998, artigos de revistas e } \\
\text { jornais. } \\
\text { 12- Apresentação de trabalhos e socialização de } \\
\text { descobertas a cada aula. }\end{array}$ & $\begin{array}{l}\text { 1- Dificuldade dos alunos em realizar uma } \\
\text { leitura sistemática dos textos extra- } \\
\text { classe. } \\
\text { 2- Escolha dos textos para subsidiar o } \\
\text { primeiro módulo pela sua complexidade. } \\
\text { 3- Organização do tempo. } \\
\text { 4- Distribuição do número de aulas pelos } \\
\text { três módulos a fim de destinar maior } \\
\text { número de encontros para o módulo 3: } \\
\text { relações entre universidade e sociedade. } \\
\text { 5- Número de alunos por turma. } \\
\text { 6- Uso de textos muito complexos para } \\
\text { turmas de alunos que no geral são } \\
\text { ingressantes. } \\
\text { 7- Não participação homogênea das turmas } \\
\text { ou baixa participação. } \\
\text { 8- Dificuldade do aluno de expressar-se } \\
\text { oralmente. }\end{array}$ \\
\hline
\end{tabular}

QUADRO 9 Estratégias e dificuldades na operacionalização da Unidade de Aprendizagem Universidade e Sociedade.

Também é útil destacar a forma como os professores expressam a importância do processo vivido, a consciência do professor quanto à importância de decisões coletivas sobre como conduzir um ambiente de aprendizagem:

[...] em termos gerais avalio o primeiro semestre de docência na disciplina como uma experiência altamente positiva.... Acredito que, por ter sido pensada coletivamente, a disciplina foi capaz de incorporar uma série de inovações de grande valor para a abordagem de questões contemporâneas importantes para a formação universitária em todas as áreas. Além disso, a criação de um programa capaz de articular de forma mais eficiente o trabalho dos professores que atuam na disciplina também foi decisiva. 
Ao que parece, a forma como o processo foi desenvolvido e as mudanças ocorridas no fazer docente foram os principais benefícios da experiência desenvolvida.

Por último, cabe destacar que essas Unidades de Aprendizagem foram positivamente avaliadas pelos alunos no processo de avaliação on-line (sistemático para todas as disciplinas, em todos os semestres) e ainda houve manifestações de alunos para coordenações de curso altamente positivas quanto a dinâmica e processo de aprendizagem vividos, tal como expresso por escrito na avaliação on-line por um acadêmico de engenharia:

[...] Nessas férias, fiz a cadeira Universidade e Sociedade, a antiga Realidade brasileira. Confesso que me surpreendi, pois todos alam que é uma cadeira "caça-níqueis", porém, ao contrário do que esperava, tive ótima lições e aprendi muito. Em um dos trabalhos que tivemos que fazer (e foram bastante e com conteúdo) tínhamos que ler um texto de Clemente Ivo Juliatto e realizar algumas análises. Este texto de título "Parceiros educadores", além de outros assuntos referentes à educação, falava sobre os deveres e direitos dos aluno. Pois bem, quando li um dos parágrafos, que reproduzi abaixo, logo me veio em mente alguns bons mestres que tive, desde o ensino fundamental até hoje no ensino superior. Agradeço por terem (e continuarem sendo) bons professores.

As palavras do aluno parecem deixar claro que a função da disciplina no processo de formação foi bem entendida pelos professores e que, quando as aulas são planejadas com foco na aprendizagem, esta tende a ocorrer com maior facilidade.

\section{PERCEPÇÕES E CONSIDERAÇÕES SOBRE O PROCESSO DESENVOLVIDO}

Considerando as perguntas iniciais propostas e os objetivos deste projeto de intervenção, é possível tecer algumas considerações e aprendizagens próprias desenvolvidas durante o processo.

O comprometimento do grupo de professores e o fato de serem especialistas nas respectivas áreas proporcionaram não apenas um crescimento coletivo em termos de construção de conceitos e de conhecimentos, mas também permitiu que cada participante desenvolvesse habilidades sobre como pode ser feito um trabalho pedagógico coletivo entre professores de nível superior. O processo vivido, ao contrário do que tradicionalmente ocorre, foi, sem dúvida, uma oportunidade ímpar de vivência interdisciplinar.

Essa vivência permitiu que um mesmo fenômeno fosse examinado sob diferentes pontos de vista, sob diferentes enfoques teóricos, ao mesmo tempo em que se tornou um "terreno fértil" para discussões e reflexões sobre modelos pedagógicos e epistemológicos. Significa que, além da competência técnica e científica, a competência pedagógica foi se fortalecendo, uma vez que, durante o processo, as decisões sempre foram precedidas de reflexões coletivas 
que, por sua vez, levavam a reflexões individuais sobre o papel de cada um no processo de ensinar e aprender no nível superior de ensino.

Os professores, nessa direção, problematizaram constantemente o próprio fazer, de forma a tornar mais claro o modelo pedagógico subjacente à prática. Tornar consciente o próprio modelo pedagógico é condição para problematizá-lo, avaliá-lo e, consequentemente, aprimorá-lo.

Outro aspecto importante a destacar é a oportunidade para troca de experiências didáticopedagógicas. As diferenças entre as formas de conduzir o contexto da sala de aula e as técnicas, as atividades e os recursos utilizados foram constantemente apresentados. Tradicionalmente, o professor entra na sala de aula, ministra seus conteúdos e não tem como hábito socializar o que faz e o que decorre desse fazer docente. Em síntese, o trabalho docente é solitário e limita-se ao professor e ao seu grupo de alunos. Essa prática mostrou, portanto, que a socialização do que é feito permite sua problematização, aprimoramento e uso para promover e potencializar aprendizagens que consolidam a profissionalidade docente.

Outro aspecto a destacar é a qualidade das propostas elaboradas. Os projetos das unidades de aprendizagem atingiram um patamar que dificilmente atingiriam caso elas fossem propostas por apenas alguns professores, mesmo que especialistas.

Os resultados observados deixam claro que pouco impacto terá um projeto de curso ou uma política curricular sem que os atores responsáveis pela sua implementação (no caso, os professores) se apropriem dos seus princípios norteadores e das estratégias que podem levá-la a efeito.

São as seguintes as aprendizagens identificadas como fundamentais: (a) definir as aprendizagens dos alunos como norteadoras das decisões sobre conteúdos, metodologia, avaliação; (b) selecionar conteúdos capazes de favorecer aprendizagens definidas; (c ) selecionar estratégias metodológicas e avaliativas coerentes com as aprendizagens; (d) selecionar materiais e recursos adequados e pertinentes; (e) organizar o tempo de acordo com a complexidade das aprendizagens, entre outras. Cabe destacar que o mais importante é dar ao professor possibilidade de contrastar seu modelo pedagógico de referência e, a partir da percepção quanto às diferenças entre o tradicional e a inovação, a (re)significação da prática pedagógica.

É útil reforçar ainda que, para que uma experiência pedagógica interdisciplinar seja proveitosa, é necessário que, no ambiente, haja respeito profundo à diversidade de pensamento, à problematização e à pluralidade de idéias. Um ambiente hostil não permite o 
crescimento individual e coletivo. Nesse sentido, quem conduz o processo precisa estar atento a sua dinâmica, valorizar e estimular a participação de todos, sem deixar que haja monopolização de idéias ou ênfase a vaidades pessoais. Significa que o modelo pedagógico adotado na experiência (interacionista), ao estimular estudos, reflexões e interações entre os participantes, permitiu que os conhecimentos individuais fossem socializados e constituíssem um conhecimento coletivo mais sólido e uma proposta elaborada mais consistente para os fins a que se destinam.

Uma capacitação pedagógica desenvolvida nesse modelo torna o ambiente agradável, potencializa as decisões e reforça a necessidade de que a formação de professores precisa ser contínua e em serviço, para que os saberes construídos na experiência possam ser socializados e possam servir à aprendizagem coletiva.

Por fim, nenhum projeto de curso, tampouco uma política curricular para cursos de graduação podem ter êxito, sem que o professor entenda seu papel na orientação dos processos de ensinar e aprender. Por mais bem elaborada que possa estar uma política curricular, sem a capacitação pedagógica dos professores, ela não passará de um documento apenas elaborado para cumprir rituais acadêmicos. Nesse sentido, a formação pedagógica pode ser considerada não só importante, mas indispensável.

\section{REFERENCIAS BIBLIOGRÁFICAS}

BALLENILLA, Fernando. Enseñar investigando: como formar profesores desde la práctica? Sevilla: Díada Editora, 1995.

BEHRENS, Marilda Aparecida. A formação pedagógica e os desafios do mundo moderno. In: MASETTO, Marcos (org.). Docência na Universidade. Campinas: Papirus, 1998.

CAPRA, Fritjof. A teia da vida: uma nova compreensão científica dos sistemas vivos. São Paulo: Cultrix, 1996.

CORTELETTI, IA; RIBEIRO, LBM; STEDILE, NLR. Reflexão sobre a ação: uma estratégia de formação de professores em nível superior de ensino. Caxias do Sul, RS: EDUCS, 2002.

DEMO. Pedro. Educar pela pesquisa. Campinas (SP): Editora Autores Associados, 1996.

FÓRUM de Graduação. ForGrad 1997 a 2004: Resgatando espaços e construindo idéias. Edufu: Universidade Federal de Uberlândia, 2004. 
GARCÍA, Carlos Marcelo. A Formação de Professores: novas perspectivas baseadas na investigação sobre o pensamento do professor. In: NÓVOA, António. Os professores e sua formação. Lisboa: Dom Quixote, 1992.

GARCÍA, Carlos Marcelo. A formação de professores: novas perspectivas baseadas na investigação sobre o pensamento do professor. In: NÓVOA, Antônio. Os professores e a sua formação. Lisboa Portugal: Publicações Dom Quixote, 1992.

MASSETO, Marcos Tarciso. Competência pedagógica no professor universitário. São Paulo: Summus Editorial, 2003.

MORAES, Maria Cândida. O paradigma educacional emergente. $4^{\text {a }}$ edição. Campinas: Papirus, 2000.

PERRENOUD, Philippe. Dez novas competências para ensinar. Porto Alegre: Artes Medicas Sul, 2000.

PERRENOUD, Philippe. Ensinar: agir na urgência, decidir na incerteza, saberes $e$ competências em uma profissão complexa. $2^{\mathrm{a}}$ ed.. Porto Alegre: Artemed, 2001.

PORLÁN, Rafael e MARTÍN, José. EI diario del profesor: um recurso para la investigación en el aula. $5^{\text {a }}$ ed.. Sevilla: Díada Editora, 1997.

STEDILE, Nilva Lúcia Rech (org). Cadernos da UCS: princípios e orientações para a organização curricular dos cursos de graduação da Universidade de Caxias do Sul. Vol. 1, n 1, 2008, EDUCS.

TARDIF, Maurice. Saberes profissionais dos professores e conhecimentos universitários. Elementos para uma epistemologia da prática profissional dos professores e suas consequências em relação à formação para o magistério. Revista Brasileira de Educação. Jan/Fev/Março 2000. No 13, p. 5 a 24.

VASCONCELOS, Celso. Planejamento: plano de ensino-aprendizagem e projeto educativo. São Paulo: Cadernos Pedagógicos do Libertad-1, 1995.

VASCONCELOS, Celso. Construção do conhecimento em sala de aula. $3^{\text {a }}$ ed. São Paulo: Liberta, 1995. 